\title{
浅谈如何做好幼儿园卫生保健工作
}

刘娥

甘肃省平凉市崆峒区玄鹤幼儿园

DOI:10.32629/er.v3i3.2518

[摘 要] 学前期儿童正处在生长发育的关键时期,他们生长发育迅速,然而身体尚未发育完善,适应环境的能力和对疾病的抵抗力不足,容易受 外界各种疾病因素的干扰, 从而影响幼儿的身体健康。所以,保证供给幼儿全面合理的营养, 加强体格锻炼, 扎实有效的防病措施等,是提高幼儿健 康水平的重要环节,也是幼儿园工作的核心。

[关键词] 幼儿园; 卫生保健; 幼儿健康

幼儿园的教育方针是保教结合, 因此幼儿园的卫生保健在幼儿园的工 作中是非常重要的一项工作。这项工作综合性强, 牵扯面广, 如何做好卫生 保健工作, 充分发挥保健作用? 我认为只有科学的管理, 协调合作, 保教结 合才能确保幼儿的身心健康。学前期儿童正处在生长发育的关键时期, 他 们生长发育迅速, 然而身体尚未发育完善, 适应环境的能力和对疾病的抵 抗力不足, 容易受外界各种疾病因素的干扰, 从而影响幼儿的身体健康。所 以, 保证供给幼儿全面合理的营养, 加强体格锻炼, 扎实有效的防病措施等, 是提高幼儿健康水平的重要环节, 也是幼儿园工作的核心。本文就如可开 展卫生保健工作, 谈一些这方面的认识。

幼儿园的卫生保健工作不是一个人也不是一个部门的事。我刚接触这 项工作时, 认为卫生保健就是检查一下卫生、配合防疫部门接种一下疫苗、 给在幼儿园发生小伤小病的儿童治疗等。(据有关调查报告还有许多幼儿 园没有保健医, 有些虽有兼职保健员, 但卫生保健工作却未开展。) 随着幼 儿园的不断发展、社会对公共卫生意识的不断加强、幼儿园教育理念的更 新, 幼儿园的卫生保健工作的重要性才逐渐被认识到, 下面我从以下几个 方面谈谈我对幼儿园卫生保健管理工作的认识:

\section{1 制定各项卫生保健制度}

要想使幼儿园的卫生保健工作规范化, 必须把卫生保健工作作为全园 的一项工作来做, 必须积极与园领导进行沟通取得园领导支持, 配合园领 导制定出符合本园实际的各项卫生保健制度如: 《卫生消毒检查制度》、《健 康检查制度》、《传染病防治制度》、《疾病预防制度》、《幼儿一日生活制度》、 《晨检制度》、《幼儿园安全制度》、《幼儿伙食管理制度》、《体弱儿管理制

下学会学习、学会合作, 最终完成综合型和自主型的人才培养目标, 满足社 会对人才的需求。

另外, 教师在英语专业课的教学过程中, 还需要加强对教学重点和教 学难点内容的把握, 在课堂教学活动中, 引导学生进行探究, 从而解决实际 问题。同时, 教师还需要完善在线课程或学习平台的管理模块, 按照不同学 生的个体差异和学习情况, 为学生建立线上的个人电子档案, 最终实现对 学生的线上评价。

3. 3在混合式教学下确定学生的评价体系标准

教师还需要在混合式教学模式, 确定学生的评价体系标准, 以此来判 断学生在实际的学习过程中, 是否达到了学习指标要求的最低等级。然后, 教师可以根据其评价结果, 对学生的学习任务的完成情况进行分析, 然后 制定下一个阶段的教学目标。另外, 教师还可以利用混合式教学模式所建 立的学生评价标准的比例性和完整性以及可调性的特点, 实现评估内容和 标准之间的相互联系和制约, 最终为学生的自主学习提供有效的标尺 ${ }^{[3]}$ 。

\section{4 结束语}

度》、《体格锻炼制度》、《卫生保健宣传与培训制度》等。经园务会议讨论 通过后在全园开展实施。在落实各项卫生保健制度时积极地与各部门协调 好关系取得各部门的配合, 全园统一步调才能有效的发挥卫生保健作用, 以确保幼儿的身心健康。在各项制度落实中, 分工明确, 责任到人, 严格按 照各项制度的要求操作如:

1.1 卫生消毒。首先制定出具有可操作性的《卫生消毒操作细则及考 核》分发给保育员和伙食管理人员并组织学习, 使他们在操作时有据可依。 从入园第一时间开始该干什么, 怎么干, 达到什么要求都有明确的规定。卫 生消毒工作形成了程序化、规范化, 同时每天填写《卫生消毒记录》保证 卫生消毒工作有序进行。

1.2 晨检。早餐晨检由各班班主任在园门口迎接幼儿入园, 同时对入园 幼儿进行初步观察, 观察他们的精神状态、步态是否正常; 暴露在外的肌 肤有无皮疹, 斑块, 然后由班主任在早饭前对已入园儿童进行逐个检查, 在 检查中要做到一看 (看神情、看外表)、二问 (问孩子有没有不舒服的地方)、 三模 (对有异常的孩子摸摸额头体温是否正常)、四查(查口腔、四肢躯干 有无皮疹), 发现异常及时送到校医室, 有校医进行确诊处理。教师要对晨 检进行详细记录, 同时还要填写缺勤儿童记录和特殊儿童的跟踪记录。

\section{2 幼儿一日生活}

首先根据幼儿的生长特点与保教组共同制定幼儿的一日生活, 合理安 排幼儿课间活动, 保证幼儿每天必须有 2 小时的户外活动时间。保育员在幼 儿一日活动中要按照《幼儿生活一日护理制度》照顾好幼儿生活如: 早晨 打扫教室为幼儿创造干净、整洁、舒适的生活环境, 然后为幼儿准备好开

综上所述, 培养学生的英语自主学习能力, 是当前我国素质教育对大 学生英语教学的要求, 对于促进大学生的英语整体水平的提升有着至关重 要的现实意义。因此, 教师需要积极利用混合式的教学模式, 完善学生自主 学习的平台, 以此来提高学生的学习积极性和主动性, 最终提高英语学习 效率。

\section{[参考文献]}

[1]杨璘璘. 关于混合式教学推动学生外语自主学习能力提升的实证 研究[J].广东开放大学学报,2019,28(01):89-94.

[2]王博.混合式教学法在大学生英语自主学习中的影响[J]. 校园英 语,2019,(11):29.

[3]洪佳君,滒文娟.教育信息化下的大学英语混合式自主学习[J].中国 农村教育,2019,(5):13-14.

\section{作者简介:}

周维利(1971--), 女, 汉族, 湖南省汨罗人, 硕士研究生, 副教授, 研究 方向: 大学英语教学。 
水和漱口的淡盐水; 吃饭时安定幼儿的情绪, 注意纠正幼儿的不良坐姿和 拿筷子的方法, 观察幼儿对饭菜的反应, 和教师一起帮助幼儿纠正偏食挑 食的不良习惯, 对肥胖儿、饭量过大以及体弱的儿童要科学喂养, 同时填写 《幼儿进餐记录》及时掌握幼儿的饮食情况; 课外活动时配合教师组织照 顾好幼儿, 保证幼儿的安全; 在一日生活中和教师共同注重培养幼儿良好 的行为习惯。

疾病预防。校医根据《健康检查制度》严格审查幼儿的健康证。我园 幼儿每年必须在市妇幼保健院体检一次, 持有市妇幼保健院出具的健康证 方可入园, 并据此建立幼儿健康档案; 对篮查出的体弱儿进行个案管理并 建立体弱儿档案; 每季度对在园的幼儿进行一次视力检查和身高体重的测 量, 同时进行统计和评估。

通过评估分析, 双合率不达标的班级或视力低常率偏高的班级, 和教 研组共同对该班级找差距分析原因, 以便在以后的教学中及时纠正偏差, 使幼儿的生长发育逐步恢复正常水平; 对有异常的儿童及时与家长联系以 便得到及时矫治; 在传染病流行时期首先加强全园各环节的卫生消毒工 作。我园消毒设施齐备: 每个教室、寝室都配备了紫外线灯管, 每天对空 气消毒半小时, 每班配备红外线消毒柜一台, 幼儿的喝水杯每次喝完水都 要进行消毒; 食堂配有大型消毒柜两台, 幼儿的碗筷必须一日三消毒; “ 84 ” 消毒液是隔离室必备以保证各班的的使用 (幼儿的桌椅、塑料玩具、幼儿 能够到的门把等都要用 “ 84 ” 消毒液擦洗消毒); 保育员教会正确的洗手 方法; 幼儿被裖每月清洗一次晒两次, 幼儿使用的小毛巾每天清洗。其次 向家长宣传有关传染病的防控知识和我园采取的防控措施, 对需要隔离的 幼儿争取家长的积极配合, 尽可能切断传染源, 减少传播途径。

当发现传染病例时第一时间上报相关主管部门和防控机构, 做到早发 现、早隔离、早预防、早治疗。积极配合疾控部门做好儿童疫苗的接种工 作, 并进行疫苗接种统计。

\section{3 幼儿饮食}

3. 1 食品应有专人负责, 成立食品卫生管理委员会, 每月组织一次伙委 会会议, 对幼儿的饮食、食堂的卫生进行反馈监督, 总结经验及时解决问题, 不断提高食堂卫生的质量, 并且要严格按照《食品卫生法操作规程》进行 操作。

3.2 食品由专人按实际需要采购, 采购的食品应新鲜优质, 每天由专人
验收生、熟食品, 并且建立验收记录本。

3. 3 生食品入库后不宜存过多, 各类食品当天进当天食用, 对于可以存 储的食品按量领取, 每月底盘货一次。库房应由专人保管, 建立出入库账目, 保持库房整洁干燥, 过保质期的食品坚决不能食用。

\section{4 幼儿安全}

安全是幼儿保健中的重中之重, 安全保证不了就无从谈教育。所以幼 儿安全在每项工作中都有所体现: 从幼儿入园到离园每个环节都有安全措 施如《打卡制度》, 每个幼儿入园时必须打卡进园, 下午离园时家长必须打 卡才能接孩子; 幼儿在活动时教师必须把幼儿纳入自己的视线之内以防幼 儿发生意外伤害; 幼儿的饭菜, 开水要调制幼儿适宜的温度后才能饮用以 防惣伤; 午睡时教师和值班人员要认真交接并填写交接班记录, 交接清楚。 后勤修理工要经常检查维修各班设施和全园的大型玩具; 食堂管理人员要 监管儿童食品由采买到成品的每个环节, 确保儿童食品的安全性; 教师要 利用健康课给幼儿讲授简单的安全防范常识。

\section{5 卫生保健宣传}

每学期开园前开展健康快车、育儿知识宣传栏; 传染病流行时期还要 向家长发放相关的传染病防治措施宣传单; 还有各年龄阶段适合幼儿的运 动, 幼儿感冒期间的饮食育儿知识。每月定期给保育员和教师进行一次幼 儿生理卫生及心理卫生保健培训, 对有心理障碍的儿童及时给教师和保育 员提供咨询参考, 使教师和保育员在教学中能有意的帮助疏导幼儿。我园 的卫生保健工作正是从以上几方面开始并逐渐深入细致的发展, 已经形成 了现在的规范化管理。

\section{[参考文献]}

[1]北京师范大学实验幼儿园主编.幼儿园后勤精细化管理[M].北京师 范大学出版社,2015.

[2]刘妤,间学明.幼儿园保健医工作指南 [M].北京师范大学出版 社,2017.

[3]刘文英(总主编),田宝军,张春炬著.幼儿园安全教育常识[M].河北大 学出版社,2012.

作者简介：

刘娥(1980--), 女,甘肃平凉人, 汉族, 一级教师, 本科, 研究方向：幼 儿园卫生保健。 